\title{
CREEP BEHAVIOR AND ACOUSTIC EMISSION CHARACTERISTICS OF COAL SAMPLES WITH DIFFERENT MOISTURE CONTENT
}

\author{
Depeng MA ${ }^{1)}$, Yan $\mathrm{ZHOU}^{2)}$ * and Chuanxiao LIU $^{1)} *$ \\ ${ }^{1)}$ School of Water Conservancy and Civil Engineering, Shandong Agricultural University, Tai'an 271018, China \\ ${ }^{2)}$ Department of Resources and Civil Engineering, Shandong University of Science and Technology, Tai'an, 271019, China
}

*Corresponding author's e-mail: zhouyansdust@163.com; lchuanx@163.com

\begin{tabular}{l} 
ARTICLE INFO \\
\hline Article history: \\
Received 29 October 2018 \\
Accepted 6 December 2018 \\
Available online 12 December 2018 \\
\hline
\end{tabular}

Keywords:

Acoustic emission

Creep test

Step loading

Damage evolution

\begin{abstract}
The acoustic emission (AE) test of step-loaded samples of coal with different moisture contents was conducted using an AG-X250KN rock servo test system and an AE21C AE-monitoring system to study the influence of moisture content on the creep characteristics of coal. The results show that the moisture content influences the creep characteristics of coal samples, in that the greater the moisture content, the greater the creep deformation of the coal and the lower the creep threshold, creep strength, and creep coefficient values. The improved Burgers model can better describe the mechanical properties of creep in coal. In the transient creep stage, the coal micropores and fractures are gradually expanded, and AE activity gradually increased. In the stable creep stage, the creep deformation rate of coal tended to be stable, while new fractures and $\mathrm{AE}$ events and energy were all decreased. In the accelerated creep stage, a large number of fractures were generated in the coal, which gradually developed into unstable macrofractures. The stored energy was released rapidly in a relatively short time span, and the number and energy of AE events reached their maximum value. Therefore, the AE characteristics of coal reflect the evolutionary process of damage during creep.
\end{abstract}

\section{INTRODUCTION}

The rheological properties of rocks are important mechanical properties of rock as a material, and many rock engineering studies, including those pertaining to underground cavern, rock slope, and rock foundation engineering have demonstrated that the material's strength shows a decreasing trend under long-term static load (Yang et al., 2018; Deng et al., 2016). Owing to its different composition and structure, coal shows different rheological characteristics compared with those of other rocks, while the rheological characteristics of coal in a mine are mainly related to creep. The creep properties are obvious: with the exhaustion of shallow coal resources, and the increasing reliance on deep mining, the plastic rock zone increases of some rock mass, and then lead to instability and failure of roadway, chamber, etc. Local instability often leading to a "domino effect," whereby failure would also occur in other parts, triggering failure of roadway support and other related accidents (Wu et al., 2018; Zhang et al., 2016; Yu et al., 2015).

In many cases, instability failure of coal mass does not occur at the moment of excavation, but lags for a period, with most of the failure occurring not because of a lack of coal strength but because the internal damage accumulate gradually affected by creep (Bui et al., 2017; Liu et al., 2015). This is because the cumulative limit depends on the creep deformation and instability. For example, the American Mining Bureau (ARMRS) database contains data recorded in the past 50 years of mined strata movement and surface subsidence that is twice the real column creep instability. Particularly in many deep mines, the water-rich nature of coal seams is generally pervasive. With time, under the physical, chemical, and mechanical effects of water, the composition and structure of coal changes slightly (Gao et al., 2013; Liu et al., 2013). This influences its macro mechanical properties, and as these processes are strongly affected over time, the gradual accumulation of coal damage will eventually affect the creep deformation characteristics of the coal mass (Hu et al., 2018; Liu et al., 2017; Yang et al., 2015). Local and international scholars have successfully studied the deformation, AE, and creep characteristics of water-rich rocks under uniaxial and triaxial compression conditions (Dai et al., 2005; Fonseka et al., 1985; Ganne et al., 2007; Holcomb et al., 1993; Li et al., 2004; Lockner et al., 1992; Qin et al., 2012). However, the AE characteristics of coal under creep conditions are still poorly understood, especially the creep characteristics of water-rich coal.

In this study, AE tests were conducted under different loading rates on coal using the SHIMADZU 
Table 1 Measured parameters and uniaxial compressive results for coal specimens with different moisture contents.

\begin{tabular}{cccccc}
\hline $\begin{array}{c}\text { Specimen } \\
\text { name }\end{array}$ & $\begin{array}{c}\text { Moisture } \\
\text { content/\% }\end{array}$ & Diameter/mm & Height/mm & $\begin{array}{c}\text { Modulus of } \\
\text { elasticity/GPa }\end{array}$ & $\begin{array}{c}\text { Uniaxial compressive } \\
\text { strength/MPa }\end{array}$ \\
\hline WT1 & 0.78 & 48.94 & 87.78 & 14.76 & 17.10 \\
WT2 & 1.07 & 48.14 & 88.78 & 12.74 & 15.63 \\
WT3 & 1.36 & 48.52 & 88.12 & 9.21 & 12.13 \\
\hline
\end{tabular}

AG-X250KN rock servo test machine and AE21C AE instrument to explore the effects of different moisture contents and the characteristics of coal creep damage by AE.

\section{TEST EQUIPMENT AND METHOD}

\subsection{SAMPLE PREPARATION}

The coal samples used in the test were collected from 2304 working face with a depth of 910-1010 m of the No. 3 coal seam. In the laboratory, large block of coal were immediately processed into standard coal samples. To determine the creep characteristics of the coal samples with different moisture contents, the coal samples were divided into three groups, and there are three samples in each group, from among which, one group was selected as the natural coal samples (determination of moisture content was $0.78 \%$ ), while the other two groups were subjected to high temperature drying. Next, the two groups of dried coal samples were treated by water absorption, where the soaking time was set at 24 and $48 \mathrm{~h}$. The moisture content of these coal samples after soaking was $1.07 \%$ and $1.36 \%$, respectively. Table 1 shows the measured parameters of coal samples and the corresponding moisture content, and one typical samples of each experimental scheme were selected for analysis.

\subsection{TEST METHOD}

The creep test was conducted on the AG$\mathrm{X} 250 \mathrm{KN}$ rock servo test machine using the hierarchical loading method. In this creep test, a load of $6 \mathrm{kN}$ was used as the initial loading level for the coals with different moisture contents, and thereafter, each stress level was increased by a $2 \mathrm{kN}$ load for $20 \mathrm{~h}$ until the coal sample was destroyed at a certain loading level. To minimize the impact of the $2 \mathrm{kN}$ step loading on the coal samples, the rate of increase in loading for each load was set at $0.1 \mathrm{kN} / \mathrm{s}$.

The experimental parameters of AE21C acoustic emission instrument are as follows: sampling frequency is $10 \mathrm{MHz}$, gain is $30 \mathrm{~dB}$, threshold value is $35 \mathrm{~dB}$, impact definition time is $50 \mu \mathrm{s}$, impact interval time is $300 \mu \mathrm{s}$, adjusting threshold voltage is $1.0 \mathrm{~V}$.

Due to the dynamic stability of a given load, the energy consumption of the equipment is large, while the strength of the coal is low, such that the creep characteristics were expected to be displayed in a short timeframe. Therefore, in the design of the loading time of $20 \mathrm{~h}$ for each stress-level in the shortterm creep test, the test data were automatically collected with a time interval set to $5 \mathrm{~s}$. Thus, subtle changes could be observed in the creep process.

\section{ANALYSIS OF CREEP TEST RESULTS OF DIFFERENT WATER-CONTENT COAL SAMPLES}

\subsection{CREEP TEST RESULTS}

A uniaxial compression tests were conducted on the three groups with different moisture contents before conducting the creep test to study the effect of moisture content on the mechanical properties of coal samples, as shown in Table 1. The uniaxial compressive strength and elastic modulus of the coal samples decrease gradually with the increase in moisture contents.

Figures 1 and 2 show the results of the creep tests on the different water-bearing coal samples. The specimens have an instantaneous elastic deformation at each stage of loading, and the creep deformation rate decreases with time, and then tends to stabilize. At this stress level, the stable creep phase is reached. The greater the moisture content, the greater is the creep deformation of the coal sample during the same load stress level.

A reduction in strain with increasing time is observed in coal samples under the same stress level, because the coal sample produces a larger instantaneous elastic deformation during the loading period, which is restored when the load is stable. As the moisture content of the coal sample increases, the elastic deformation characteristics of coal samples are weakened, while the plastic deformation characteristics are enhanced correspondingly, especially in the coal sample with a moisture content of $1.36 \%$. As shown in Figure 2, the amount of elastic deformation recovery at the first stress level of the coal samples is obviously reduced.

The creep threshold values of the coal samples with different moisture contents is given in Table 2, while the threshold coefficient is the ratio of the creep threshold stress value to the creep strength. The creep threshold values the minimum stress level of creep deformation. The water content creep coefficient is the ratio of the creep strength of the coal to the instantaneous strength in its natural state. The creep threshold value, creep strength, and water content 


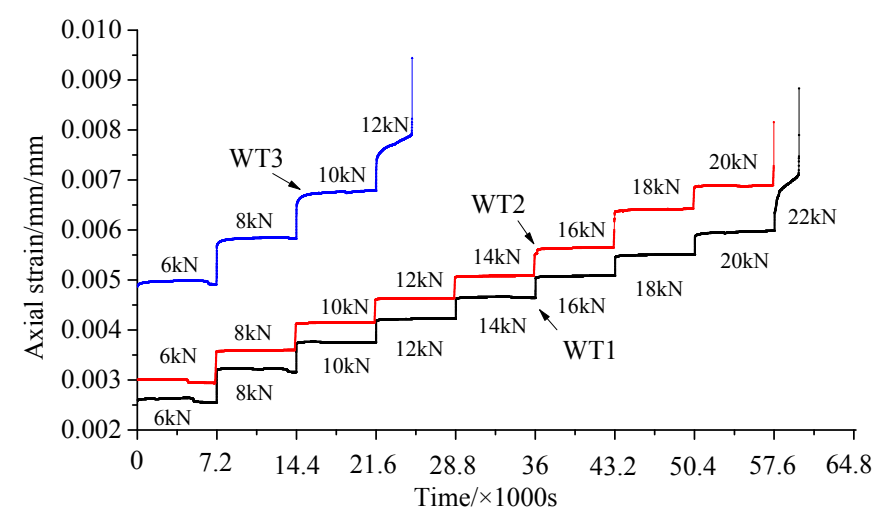

Fig. 1 Creep test results of the step loading of coal specimens with different moisture contents.

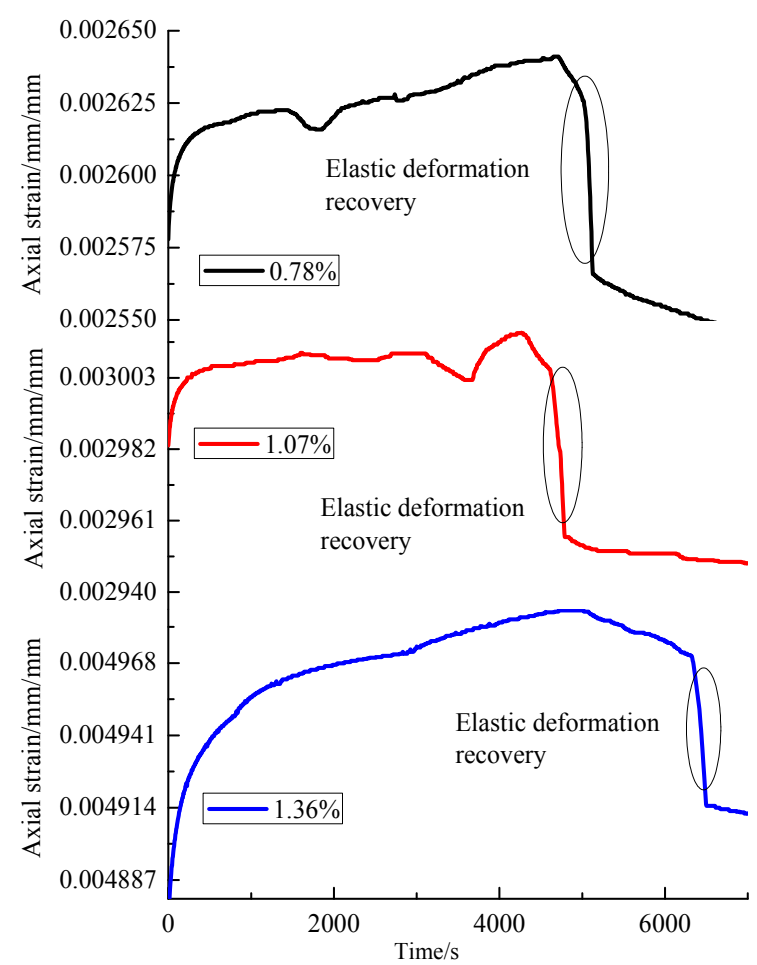

Fig. 2 Elastic deformation recovery curves at the first stress level of the coal specimens with different moisture contents. creep coefficient all decrease as the moisture content increases, indicating that the greater the moisture content, the more obvious are the characteristics of coal creep and the lower its carrying capacity.

\subsection{PARAMETERS OF COAL SAMPLE CREEP MODEL OF DIFFERENT MOISTURE CONTENT}

The total strain of the creep process on a general rock material is the sum of the following four stages: the elastic deformation ( $\left.\varepsilon_{0}\right)$, instantaneous creep stage $\left(\varepsilon_{1}(t)\right)$, stable creep stage $\left(\varepsilon_{2}(t)\right)$, and accelerated creep stage $\left(\varepsilon_{3}(t)\right)$. This can be expressed as $\varepsilon(t)=\varepsilon_{0}+\varepsilon_{1}(t)+\varepsilon_{2}(t)+\varepsilon_{3}(t)$. As shown in Figure 3 , the experimental data were fitted with cubic polynomials as follows:

$y=2 \times 10^{-13} x^{3}-4 \times 10^{-8} x^{2}+0.0023 x-44.886$

Taking the specimen WT1 as an example, the correlation coefficient is 0.979 and the fitting effect is superior.

Figure 3 shows that the creep process includes instantaneous deformation, constant velocity creep, and accelerated creep. Burgers model can better describe the creep characteristics of the first and second stages but cannot accurately describe those of the accelerated stage. By using the Mohr-Coulomb criterion, a new kind of plastic element and Burgers model were combined in series to improve the typical Burgers model, abbreviated as the modified Burgers model, which better describes the creep test (Yuan et al., 2006). This model was used to describe the

Table 2 Creep test results of coal specimens.

\begin{tabular}{lrrr}
\hline Specimen name & WT1 & WT2 & WT3 \\
\hline Creep threshold/MPa & 8.566 & 6.316 & 4.305 \\
Threshold coefficient & 0.779 & 0.597 & 0.752 \\
Creep strength/MPa & 10.989 & 10.573 & 5.724 \\
Water content creep coefficient & 0.643 & 0.618 & 0.335 \\
\hline
\end{tabular}




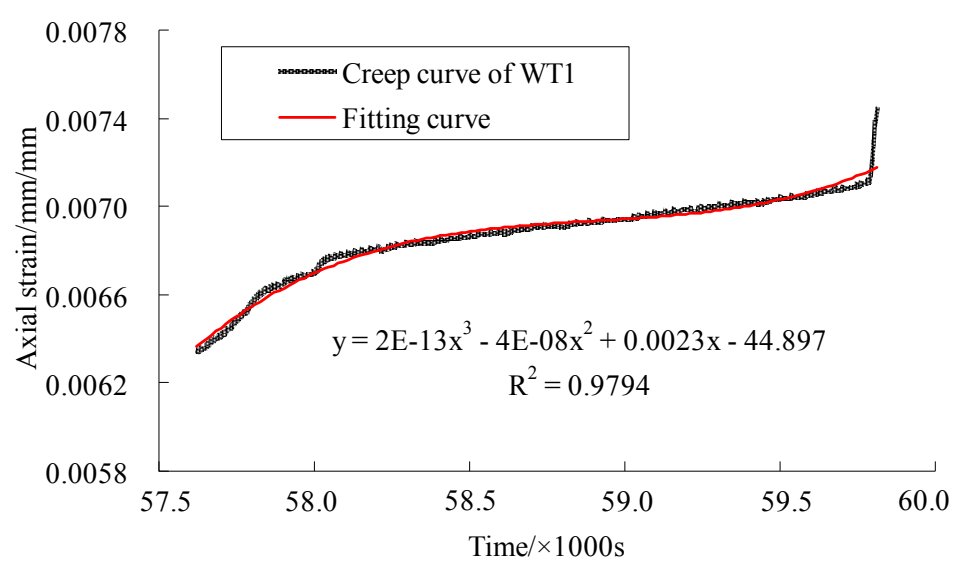

Fig. 3 Fitting creep curve of coal specimen with the moisture content of $0.78 \%$.

Table 3 Fitted creep model parameters.

\begin{tabular}{lccccc}
\hline $\begin{array}{l}\text { Moisture } \\
\text { content/\% }\end{array}$ & $\begin{array}{c}\text { Model parameters } \\
\text { K bulk viscosity } \\
\text { coefficient/GPa·s }\end{array}$ & $\begin{array}{c}\text { K bulk shear } \\
\text { modulus/GPa }\end{array}$ & $\begin{array}{c}\text { M bulk viscosity } \\
\text { coefficient/GPa·s }\end{array}$ & $\begin{array}{c}\text { M bulk shear } \\
\text { modulus/GPa }\end{array}$ & $\begin{array}{c}\text { Bulk } \\
\text { modulus/GPa }\end{array}$ \\
\hline 0.78 & $7.01 \times 10^{6}$ & 1.59 & $1.71 \times 10^{6}$ & 1.57 & 1.81 \\
1.7 & $6.20 \times 10^{6}$ & 1.26 & $1.33 \times 10^{6}$ & 1.41 & 1.29 \\
1.36 & $3.35 \times 10^{6}$ & 0.62 & $0.84 \times 10^{6}$ & 1.5 & 1.63 \\
\hline
\end{tabular}

properties of the creep mechanics of coal. The strain of plastic element was zero before the stress reached the yield stress of Mohr-Coulomb criterion and obeyed Mohr-Coulomb plastic flow rule when the stress was greater than or equal to the yield stress.

When $\sigma<\sigma_{\mathrm{s}}$, the Modified Burgers model is a typical Burges creep model. Its constitutive equation is as follows:

$\varepsilon(t)=\frac{2 \sigma}{9 K}+\frac{\sigma}{3 G_{2}}+\frac{\sigma}{3 G_{1}}-\frac{\sigma}{3 G_{1}} \exp \left(-\frac{G_{1}}{\eta_{1}} t\right)+\frac{\sigma}{3 \eta_{2}} t$

In the formula, $\eta_{1}$ is viscosity coefficient of Kelvin bulk, GPa. s; $\eta_{2}$ is viscosity coefficient of Maxwell bulk, GPa. s; $K$ is bulk modulus, GPa; $G_{1}$ is elastic modulus of Kelvin bulk, GPa; $G_{2}$ is elastic modulus of Maxwell bulk, GPa.

When $\sigma \geqslant \sigma_{\mathrm{s}}$, the viscoelastic and viscoplastic strain rates are compatible. The model viscoelastic body is composed of Kelvin body and Maxwell body in series, and the plastic properties are realized by Mohr-Coulomb criterion.

Mohr-Coulomb yield criterion includes shear and tension criteria.

Shear yield function:

$$
\begin{aligned}
& f=\sigma_{1}-\sigma_{3} N_{\varphi}+2 C \sqrt{N_{\varphi}} \\
& N_{\varphi}=\frac{1+\sin \varphi}{1-\sin \varphi}
\end{aligned}
$$

Tensile yield function:

$f=\sigma^{\prime}-\sigma_{3}$

In the formula: $C$ is the cohesive force of the material; $\varphi$ is the internal friction angle; $\sigma^{\prime}$ is the tensile strength; $\sigma_{1}, \sigma_{3}$ is the maximum and minimum principal stress.

The creep test results for the WT1, WT3, and WT3 coal samples were analyzed, and the creep model parameters obtained (Table 3) were analyzed using the parameter regression formula of the improved Burgers creep model. According to Table 3, the obtained creep-model parameters were lower, except for the volume modulus, with higher moisture contents. This further shows that the greater the moisture content of coal samples, the more obvious are the creep characteristics.

\subsection{CREEP CHARACTERISTICS OF ROCK AE OF COAL}

The $\mathrm{AE}$ of a rock material is an expression of the stress in the exterior environment, where the internal accumulation of elastic-plastic energy reaches a certain critical value after the production of microfractures and their extension, and is accompanied by the formation of the release of an elastic wave or a stress wave. The destruction of rock by compressive deformation is accompanied by $\mathrm{AE}$, the information from which contains precursor information about the abundant rock damage caused 


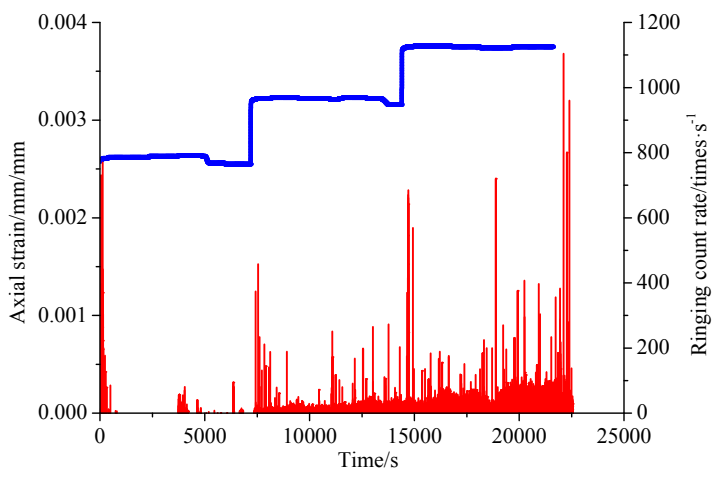

(a)

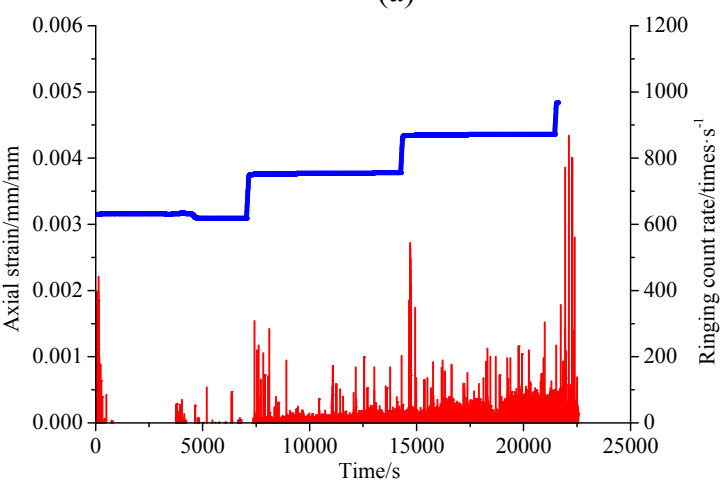

(b)

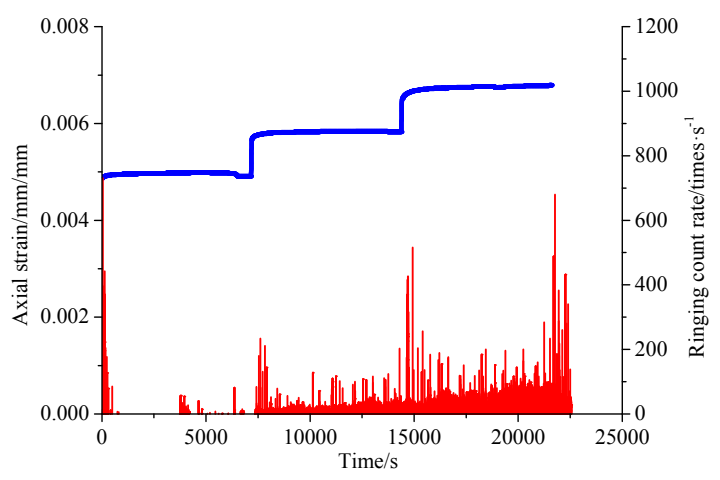

(c)

Fig. 4 Ringing count rate of coal samples with moisture contents of (a) $0.78 \%$, (b) $1.07 \%$, (c) $1.36 \%$.

by its gradual destruction. AE information obtained during the rock compression failure process is used to predict the progressive damage process of the rock. It is particularly important in monitoring the deformation in coal mines and coal pillar stability.

AE comprises many parameters. In this study, we selected the AE ringing count rate to analyze the AE characteristics of the creep process of coal. The ringing count rate of $\mathrm{AE}$ is the number of rings observed during a sampling interval, which reflects the frequency of AE emission to a certain extent, as well as the amplitude of the AE signal. Because of the different stress levels of the coals with different moisture contents used in the coal sample creep tests, the AE information for the first three stress levels of coal with different moisture content was analyzed, as shown in Figure 4.

At the beginning of the experiment, the primary fractures in the coal samples with different moisture contents were subjected to the process of compaction forming new fractures. Under the action of the initial stress level, the step loading process of each stage of the load had enhanced AE activity, but this gradually weakened to a steady state when the load became stable. With the increase in stress level, the AE ringing count and energy were correspondingly increased but it was lower relative to the AE activity during the creep phase. This was probably because under the action of low stress levels, although the microfractures are formed under compaction inside the coal specimen, the stability of the whole structure of the coal is less.

The three stages of the creep process, namely, the transient, stable, and accelerated creep stages, were obtained for the coals with different moisture contents, when the loading level was greater than the creep- stress threshold of the rock, as shown in Figure 5.

1. In the transient creep stage, micropores and fractures of the coal gradually expanded, and both the AE ringing and energy were higher than those in the first few steps. The strain rate decreased with the loading time, and the $\mathrm{AE}$ ringing count and energy decreased accordingly, while the axial strain gradually stabilized.

2. When the creep entered the stable stage, the creep rate of the coal tended to be stable and the surface showed a slight fracture. Due to the complexity of the internal structure of the coal specimen, the linear relationship between strain and time of the stable creep stage was not very obvious. The AE ringing was weaker than at the transient creep stage and tended to be stable however, compared with the previous stress levels, the AE activity is more obvious, and the fluctuation of the $\mathrm{AE}$ ringing indicates that slight rupture and penetration of the structure still occurs in this stage.

3. This was followed by a brief period of attenuation before the test piece entered the accelerated creep stage, and then the AE ringing count increased significantly with the strain intensity. The AE ringing count reached its maximum during the brittle fracture of the coal. As the loading system adopted the load control mode, the axial strain rate increased dramatically, and immediately after a very short time, the specimen failure occurred. The coal specimen showed plastic failure, and the AE activity disappeared after the specimen damage.

This shows that the microstructure of coal changed under the action of water, resulting in the weakening of the degree of rupture and $\mathrm{AE}$ activities. 


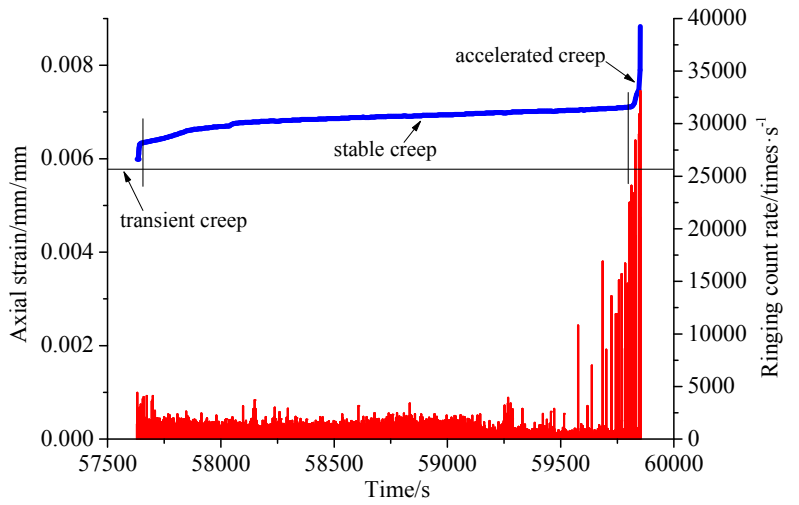

(a)

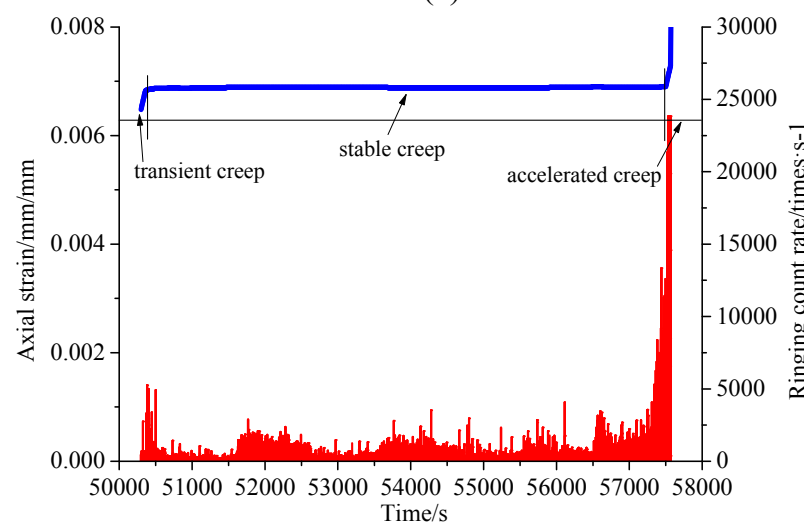

(b)

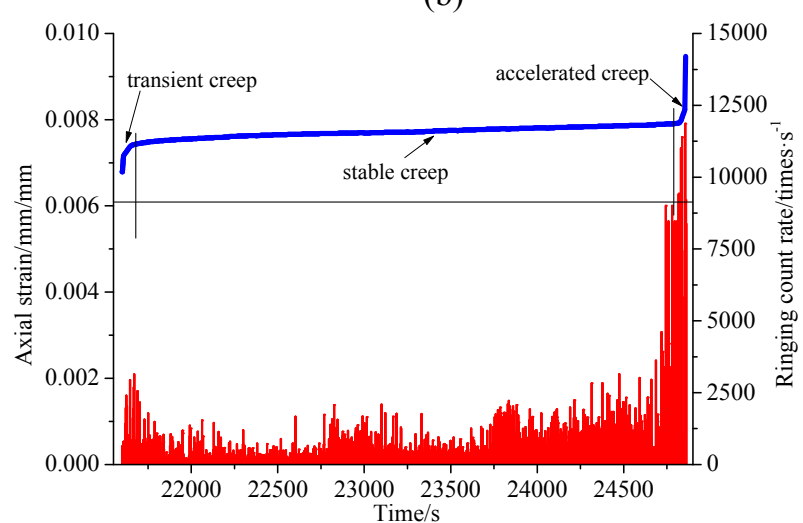

(c)

Fig. 5 Ringing count rate of $A E$ of the final stress level of the coal sample with moisture contents of (a) $0.78 \%, \quad$ (b) $1.07 \%$, (c) $1.36 \%$.

\section{EVOLUTION ANALYSIS OF COAL DAMAGE 4.1. DAMAGE ANALYSIS OF WATER-BEARING COAL SAMPLE}

To illustrate the damage effect of moisture content on the coal samples, the latter were simplified as fully elastic materials, and the damage status of coal samples with different moisture contents was roughly understood through the change of the elastic modulus of the coal samples (Zhang et al., 2016). The experimental setting assumed zero damage for the coal sample with natural moisture content. With the increase in moisture content, the damage increased gradually, and the damage value was positive.
The relationship between the elastic modulus $E$ and the moisture content (Fig. 6) was fitted and the following expression was obtained:

$y=-13.94 x^{2}+12.97 x+13.13$

The damage factor expression is: $D(v)=1-\omega$

The elastic modulus was normalized and the continuity factor was obtained as, where $E_{v}$ is the elastic modulus of the coal sample with different moisture contents (Table 1), and $E_{o}$ is the elastic modulus of the natural coal sample.

A damage curve $(D(v))$ with different moisture contents was drawn as shown in Figure 6. The fitting of the $D(v)-v$ curve was obtained as follows:

$y=0.9446 x^{2}-0.879 x+0.1105$

With the increase in the moisture content, the damage value of the coal samples increased. When the moisture content was $0.78-1.07 \%$, the damage value increased slowly, but when the moisture content increased from $1.07 \%$ to $1.36 \%$, the damage value increased rapidly.

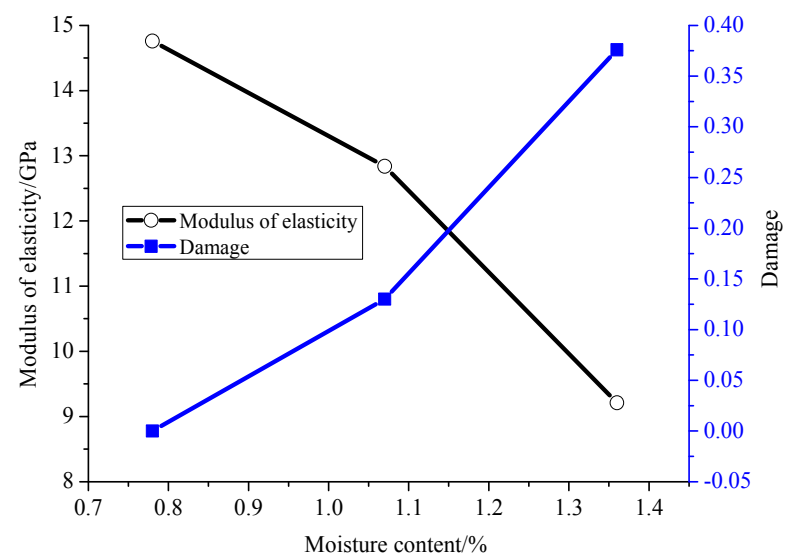

Fig. 6 Damage of the coal specimens with different moisture contents.

\subsection{ANALYSIS OF MICROSCOPIC CHARACTERISTICS OF COAL SAMPLES WITH DIFFERENT MOISTURE CONTENTS}

Typical coal samples were selected for SEM test (magnify 500 times), and the microfissures observed under scanning electron microscopy were photographed, as shown in Figure 1. WT1 coal sample has small moisture content and small internal damage, showing obvious brittle failure along the axis; WT3 coal sample has the largest moisture content, its micro-pore, micro-fissure and damage are larger, and the damage is obvious plastic failure; the moisture content of WT2 is between the two, and its failure mode is also between the two. 


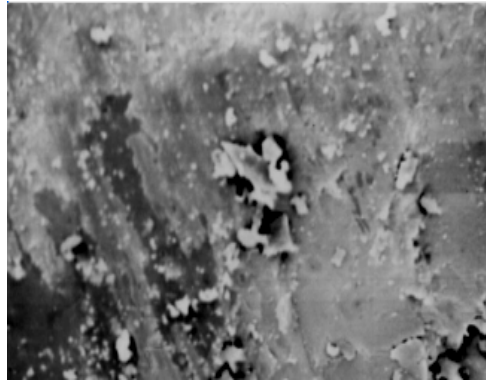

(a)

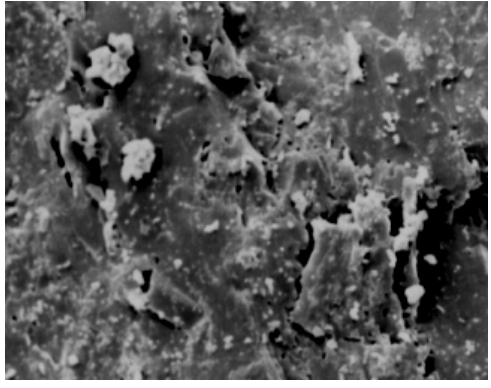

(b)

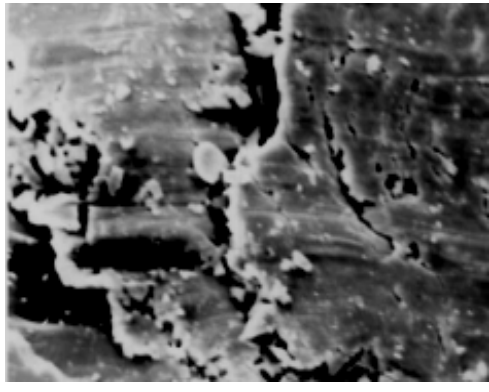

(c)

Fig. 7 Sem photographs of typical coal samples. (a)WT1; (b)WT2; (c)WT3

\subsection{ANALYSIS OF CREEP DAMAGE EVOLUTION OF COAL}

From the microscopic point of view, the damage includes a large number of microfractures distributed throughout the coal, with new fractures continuing to be produced and converge into macroscopic fractures. When the material was subjected to load, the localized microfractures affected the strength of the material before the occurrence of the macroscopic fractures. At a low stress level, although the coal inside the primary fracture undergoes the process of compaction and develops new fractures, this does not severely impact its internal structure, resulting in minor ringing. This phase involves only minor damage. When the stress level is greater than the creep stress threshold, microfractures are initiated in the coal and expand steadily, whereby the AE, ringing counts, and energy are greatly enhanced. After the specimen enters the accelerated creep stage, a large number of fractures are generated in the coal, and these gradually develop into unstable macrofractures. The stored energy is released rapidly in a relatively short time, and the number of AE ringing counts increases dramatically.

The process of damage evolution in coal during the creep process is well reflected by the $\mathrm{AE}$ characteristics of the coal. Therefore, it is important to predict the creep deformation characteristics of coal using $\mathrm{AE}$ information in order to monitor the deformation of coal and determine the significance of the long-term stability of coal pillars.

\section{CONCLUSIONS}

- The creep test using coal samples with different moisture content showed that the moisture content of a coal sample significantly affects its creep properties. With the increase of moisture content, the creep deformation of a coal sample quantitatively increases, while the threshold value, strength, and coefficient of the creep decrease. In addition, the creep test showed that for coal samples under the same stress level, an elastic deformation recovery phenomenon is observed, which is clearly reduced with increasing moisture content, while plastic degeneration is clearly increased.

- The creep deformation is not obvious at all stress levels before the stress threshold is reached, but obvious creep failure occurs when the loading level is greater than the threshold. The modified Burgers model is better than the conventional Burgers creep model in describing the mechanical characteristics of creep in coal.

- Under the action of a low stress level, although microfractures are observed to form under compaction within the coal, the AE ringing count and energy are relatively small, and indicate only a slight effect of the low stress level on the stability of the whole structure of the coal.

- In the transient creep stage, the strain rate decreases gradually with the loading time, the micropores and fissures gradually expand, and the AE activity gradually increases. In the stable creep stage, the creep deformation rate tends to be stable, but the creep curve is approximately linear, while new fractures are weaker and the AE signal is more stable. In the accelerated creep stage, fractures are produced that gradually develop into macroscopic failure and show a rapid release of stored energy in a relatively short period of time. The AE signal is significantly enhanced, but after the specimen suffers damage, the AE activities gradually disappear. The AE characteristics of coal reflect the damage evolution during the creep process.

- For coals with different moisture contents, the creep process in terms of the three stages of AE, as measured by the ringing count rate, is basically the same. However, the high moisture content of coal delivers a ringing count rate that is lower than for coal samples with low moisture content, indicating that under the action of water, the internal microstructure of coal changes, leading to weakening of its degree of rupture and $\mathrm{AE}$ activities. 


\section{ACKNOWLEDGMENTS}

This research was funded by the project of Shandong Province Higher Educational Science and Technology Program, for Program Development grant number J18KA195. This research was also partially funded by the Key of Shandong Province, grant number Research 2018GNC110023.

\section{REFERENCES}

Bui, T.A., Wong, H., Deleruyelle, F., Xie, L.Z. and Tran, D.T.: 2017, A thermodynamically consistent model accounting for viscoplastic creep and anisotropic damage in unsaturated rocks. Int. J. Solids Struct., 117, 26-38. DOI:10.1016/J.IJSOLSTR.2017.04.015

Dai, S.T. and Labuz, J.F.: 2005, Damage and failure analysis of brittle materials by acoustic emission. Rock Mech. Rock Eng., 38, 1, 1-19. DOI: 10.1007/S00603-004-0031-6

Deng, H.F., Zhou, M.L., Li, J.L., Sun, X.S. and Huang, Y.L.: 2016, Creep degradation mechanism by waterrock interaction in the red-layer soft rock. Arab. J. Geosci., 9, 12, 601-613. DOI: $10.1007 / \mathrm{S} 12517-016-2604-6$

Fonseka, G.M., Murrell, S.A.F. and Barnes, P.: 1985, Scanning electron microscope and acoustic emission studies of crack development in rocks. Int. J. Rock Mech. Min. Sci. Geomech. Abstracts, 22, 5, 273-289. DOI: 10.1016/0148-9062(85)92060-1

Ganne, P., Vervoort, A. and Wevers, M.: 2007, Quantification of pre-break brittle damage correlation between acoustic emission and observed microfracture. Int. J. Rock Mech. Min. Sci, 44, 5, 720-729. DOI: 10.1016/J.IJRMMS.2006.11.003

Gao, Y.N., Gao, F. and Ronald, Y.M.: 2013, Rock creep modeling based on discontinuous deformation analysis. Int. J. Min. Sci. Technol., 23, 5, 757-761. DOI : 10.1016/J.IJMST.2013.08.021

Holcomb, D.J.: 1993, General theory of Kaiser effect. Int. J. Rock Mech. Min. Sci. Geomech. Abstracts, 30, 7, 929-935. DOI: 10.1016/0148-9062(93)90047-H

Hu, K.F., Feng, Q., Li, H. and Hu, Q.: 2018, Study on creep characteristics and constitutive model for Thalam rock mass with fracture in tunnel. Geotech. Geol. Eng., 36, 2, 827-834. DOI: 10.1007/S10706-017-0357-Y

Li, S.L., Yin, X.G., Wang., Y.J. and Tang, H.Y.: 2004, Study on acoustic emission characteristics of uniaxial compressive rock failure. Chin. J. Rock Mech. Eng., 23, 5, 2499-2503, (in Chinese).

DOI: $10.3321 /$ J.ISSN:1000-6915.2004.15.003
Liu, H.Z., Xie, H.Q., He, J.D., Xiao, M.L. and Zhuo, L.: 2017, Nonlinear creep damage constitutive model for soft rocks. Mech. Time Depend. Mat., 21, 1, 73-96. DOI : 10.1007/S11043-016-9319-7

Liu, L., Wang, G.M., Chen, J.H. and Yang, S.: 2013, Creep experiment and rheological model of deep saturated rock. T. Nonferr. Metal. Soc., 23, 2, 478-483. DOI : 10.1016/S1003-6326(13)62488-7

Liu, Z.B., Xie, S.Y., Shao, J.F. and Conil, N.: 2015, Effects of deviatoric stress and structural anisotropy on compressive creep behavior of a clayey rock, Appl. Clay Sci., 114, 491-496. DOI:10.1016/J.CLAY.2015.06.039

Lockner, D.A., Byerlee, J.D., Kuksenko, V., Ponomarev, A. and Sirotin, A.: 1992, Observation of quasi-static fault growth from acoustic emissions. In: Evans, B., Wong, T.-F (eds.). Fault mechanics and transport properties of rocks. New York, Academic Press, 3-31.

Qin, H., Huang, G. and Wang, W.Z.: 2012, Experimental study of acoustic emission characteristics of coal samples with different moisture contents in process of compression deformation and failure. Chin. J. Rock Mech. Eng., 31, 6, 1115-1120, (in Chinese). DOI: 10.3969/J.ISSN.1000-6915.2012.06.004

Wu, X.Z., Jiang, Y.J., Guan, Z.C. and Wang, G.: 2018, Estimating the support effect of the energy-absorbing rock bolt based on the mechanical work transfer ability. Int. J. Rock Mech. Min. Sci, 103, 168-178.

Yang, L. and Li, Z.D.: 2018, Nonlinear variation parameters creep model of rock and parametric inversion. Geotech. Geol. Eng., 36, 5, 2985-2993. DOI: $10.1007 / \mathrm{S} 10706-018-0517-8$

Yang, S.Q., Xu, P. and Ranjith, P.G.: 2015, Damage model of coal under creep and triaxial compression. Int. J. Rock Mech. Min. Sci, 80, 337-345. DOI: 10.1016/J.IJRMMS.2015.10.006

Yu, Z., Xu, W.Y., Shao, J.F., Zhao, H.B. and Wei, W.: 2015, Experimental investigation of creep behavior of clastic rock in Xiangjiaba hydropower project. Water Sci. Eng., 8, 1, 55-62. DOI:10.1016/J.WSE.2015.01.005

Yuan, H.P., Cao, P., Xu, W.Z. and Chen, Y.J.: 2006, Visco-elastop-lastic constitutive relationship of rock and modified Burgers creep model. Chin. J. Geotech. Eng., 28, 6, 796-799. DOI:10.3321/J.ISSN:1000-4548.2006.06.024

Zhang, Y., Shao, J.F., Xu, W.Y. and Jia, Y.: 2016, Timedependent behavior of cataclastic rocks in a multiloading triaxial creep test. Rock Mech. Rock Eng., 49, 9, 3793-3803. DOI: 10.1007/S00603-016-0948-6 